\title{
A IMPLANTAÇÃO DA LOGÍSTICA REVERSA DE EMBALAGENS DE MEDICAMENTOS: UM ESTUDO DE CASO EM UMA INDÚSTRIA VETERINÁRIA DE MÉDIO PORTE
}

\section{ARTIGO ORIGINAL}

ROVIERO, Fernanda Duarte ${ }^{1}$

MELLO, George Gustavo Ricardo ${ }^{2}$

SOARES, Letícia Furigo ${ }^{3}$

ANJOS, Alexander Pitta dos ${ }^{4}$

ROVIERO, Fernanda Duarte. Et al. A implantação da Logística Reversa de Embalagens de Medicamentos: Um estudo de caso em uma Indústria Veterinária de médio porte. Revista Científica Multidisciplinar Núcleo do Conhecimento. Ano 05, Ed. 10, Vol. 18, pp. 31-44. Outubro de 2020. ISSN: 2448-0959, Link de acesso: https://www.nucleodoconhecimento.com.br/engenharia-de-

producao/industria-veterinaria

\section{RESUMO}

A preocupação ambiental é cada vez maior em todos os setores da sociedade, no qual essa questão se tornou o foco no meio empresarial estimulando a responsabilidade das empresas sobre o fim da vida de seus produtos. Como forma de minimizar os males causados pelas embalagens ao meio ambiente, muitas empresas

1 Terminando a graduação em Engenharia de Produção em Dezembro/2020.

2 Terminando a graduação em Engenharia de Produção em Dezembro/2020.

${ }^{3}$ Terminando a graduação em Engenharia de Produção em Dezembro/2020.

${ }^{4}$ Orientador. Mestrado Profissional em Engenharia de Produção, pós graduação em Engenharia de Segurança do trabalho e graduação em Engenharia de Produção. 
têm adotado de forma estratégica a ferramenta logística reversa que além de contribuir para o bem estar da sociedade e ao meio ambiente, reduz os custos operacionais de muitas empresas através do reaproveitamento de materiais e embalagens. Apesar de ser considerada uma das ferramentas mais eficazes para a melhoria dos processos produtivos através do reaproveitamento de resíduos sólidos, tem sido pouco empregada em indústrias de medicamentos veterinários. O objetivo desta pesquisa é descrever a implementação da Logística Reversa em uma indústria de medicamentos veterinários. A investigação de caráter qualitativo tem como técnica de pesquisa o estudo de caso da aplicação da ferramenta logística reversa em uma empresa de médio porte e utilizará como instrumentos para a coleta dos dados a pesquisa documental para detalhar como foram os procedimentos de implantação e os impactos gerados na organização. O uso da logística reversa na indústria de medicamentos veterinários mostrou-se eficaz na diminuição de resíduos sólidos e impacto socioambiental, além de redução dos custos com embalagens, mostrando resultados semelhantes aos alcançados pelas empresas farmacêuticas de grande porte.

Palavras-chave: Logística Reversa, indústria de medicamentos veterinários.

\section{INTRODUÇÃO}

Com o aumento da concorrência em todos os setores industriais intensificados nos últimos anos pelo avanço tecnológico e também pela necessidade de respostas cada vez mais rápidas para atender as necessidades dos clientes, fez com que muitas organizações observassem a importância de se ter um departamento para cuidar de sua logística. De acordo com Ballou (2001) foi a partir desse momento que surgiu o conceito de Logística Empresarial.

Ainda de acordo com Ballou (2001) a logística é entendida como o gerenciamento dos fluxos de materiais, no qual atua desde a origem da matéria prima até a distribuição dos produtos acabados para os centros de distribuição e também para o cliente final. 
No entanto, os ciclos de vida dos produtos na cadeia produtiva não terminam após os mesmos serem entregues para os seus clientes, ou seja, após o consumo dos produtos são descartadas todas as embalagens que o acompanharam para manter a qualidade e integridade dos mesmos.

Essas embalagens por sua vez se tornaram um grande problema para o meio ambiente e para a sociedade como um todo, devido ao grande volume de resíduos que são gerados diariamente.

De acordo com Leite e Pawlowsky (2005) a preocupação ambiental é cada vez maior em todos os setores da sociedade, no qual essa questão se tornou o foco no meio empresarial estimulando a responsabilidade das empresas sobre o fim da vida de seus produtos.

Como forma de minimizar os males causados pelas embalagens ao meio ambiente, muitas empresas têm adotado de forma estratégica a ferramenta logística reversa que além de contribuir para o bem estar da sociedade e ao meio ambiente, reduz os custos operacionais de muitas empresas através do reaproveitamento de materiais e embalagens. (ADLMAIER; SELLITTO, 2007; MOTTA, 2011).

De acordo com Mueller (2005) o foco da logística reversa seria o reaproveitamento dos materiais utilizados e a reciclagem, ou seja, empresas preocupadas com o fim de vida de seus produtos e a preservação ambiental.

Já para Garcia (2006) a logística reversa serve para complementar a logística tradicional, enquanto a última tem o objetivo de levar a matéria prima ou o produto do fornecedor até o cliente final a logística reversa possuí o caminho inverso da cadeia produtiva, ou seja, as embalagens passam pela reciclagem até completar o ciclo de vida útil do produto.

De forma geral, logística reversa (ou inversa) é a área da logística que planeja, opera e controla o fluxo e as informações referentes ao retorno dos bens produzidos após 
sua venda. Uma de suas aplicações é controlar políticas de devolução e troca de produtos.

De acordo com o Ministério do Meio Ambiente (2020) aproximadamente um quinto do lixo no Brasil é composto por embalagens, ou seja, aterros e lixões ficam lotados devido ao descarte incorreto dessas embalagens e assim causam impactos ambientais que o consumidor final poderia evitar se soubesse fazer a correta separação e destinação do lixo.

Muitas organizações tiveram sucesso com a implementação da Logística Reversa, dentre as quais pode-se destacar a Indústria União Química Farmacêutica Nacional S.A, que com a implantação do Plano de Gerenciamento de Resíduos Sólidos Industriais estabeleceu melhorias quantificáveis nos Procedimentos Operacionais Padrão (POP), que proporcionaram ao mesmo tempo alternativas para reduzir custos e criar valor. (SHEHATA, 2012).

Apesar dos trabalhos de Stocher (2018); Castro et al. (2019) e Bueno et al. (2016), demonstrarem com sucesso a implantação da Logística Reversa em indústrias farmacêuticas nos últimos anos, nota-se pouca adoção da ferramenta em indústrias de medicamentos veterinários.

No sentido de contribuir para um maior esclarecimento destes aspectos voltados a implantação da Logística Reversa em indústrias de medicamentos veterinários, 0 problema que se apresenta nesta pesquisa pode ser representado pela questão a seguir:

Quais os impactos e as limitações para implementação da Logística Reversa em uma indústria de medicamentos veterinários?

Como forma de contribuir para a literatura específica da área, o objetivo deste trabalho é descrever a implementação da Logística Reversa em uma indústria de medicamentos veterinários. 
Para a elaboração da pesquisa partiu-se de uma revisão bibliográfica sobre o tema central (Logística Reversa) e tomou como base a aplicação dos conceitos estudados em um caso real em uma indústria de medicamentos de médio porte que atua no setor veterinário. A pesquisa caracterizada como um estudo de caso em uma empresa do interior do estado de São Paulo, é de natureza aplicada e cunho qualitativo e está centrada no setor de Embalagens onde buscará ter o melhor aproveitamento do descartes desses materiais e assim podendo beneficiar tanto na parte de redução de custos como na parte sustentável.

\section{A LOGÍSTICA E A LOGÍSTICA REVERSA}

No setor empresarial a Logística é um fator muito importante para a empresa quanto a sua necessidade de ter um produto que atende todas as necessidades do seu cliente e sua posição no mercado. Seu processo também é responsável pelo planejamento, operação e controle do fluxo de mercadorias desde o fabricante até o consumidor final.

Uma das vantagens da Logística é sua integração em todos os setores da empresa e assim favorecendo todos a trabalharem juntos, buscando o trabalho em equipe, a garantia do cumprimento dos objetivos e dos prazos estipulados.

Define-se conforme Ballou (2006, p. 27):

Logística é o processo de planejamento, implementação e controle do fluxo eficiente e eficaz de mercadorias, serviços e das informações relativas, desde o ponto de origem até o ponto de consumo com o propósito de atender às exigências dos clientes.

Já a Logística Reversa é muito comparada com a definição de reciclagem ou reutilização. Ela também é responsável pela parte de planejamento, operação e controle do fluxo dos bens de pós-venda e pós-consumo e assim buscando agregar valor em diversos setores, como: logístico, econômico, ecológico e sustentabilidade. (ADLMAIER; SELLITTO, 2007). 
Uma das definições pesquisadas de Logística Reversa é do autor Leite (2005, p.1617), assim definida:

Entendemos a logística reversa como a área da logística empresarial que planeja, opera e controla o fluxo e as informações logísticas correspondentes, do retorno dos bens de pós-venda e de pós-consumo ao ciclo de negócios ou ao ciclo produtivo, por meio dos canais de distribuições reversas, agregando-lhes valor de diversas naturezas: econômico, ecológico, legal, logístico, de imagem corporativa, entre outros.

A utilização da Logística Reversa não será somente um ganho para o meio ambiente uma vez que os resíduos estarão retornando aos seus devidos destinatários mas também para as empresas que estão buscando essa utilização, pois assim será um diferencial em sua imagem e isso vale e muito em um mercado tão disputado como $o$ que temos atualmente.

\section{A INDÚSTRIA DE MEDICAMENTOS VETERINÁRIOS}

A indústria farmacêutica veterinária é muito parecida com a indústria farmacêutica humana, ou seja, é classificada em quatro classes terapêuticas: parasiticidas, biológicos (vacinas), tratamento de infecções, aditivos alimentares e outros farmacêuticos. (BARRETO, 2013)

Em decorrência dessa semelhança, empresas que atuam em uma área também acabam atuando com a outra, é o caso das empresas Pfizer, Novartis e Bayer que atuam tanto na indústria farmacêutica humana quanto na indústria farmacêutica veterinária.

Essas empresas são caracterizadas de duas maneiras: grandes empresas internacionais químico farmacêuticas e empresas nacionais de menor porte.

O artigo $2^{\circ}$ do Decreto 5.053/04 assim define os produtos da indústria veterinária:

Entende-se por produto veterinário toda substância química, biológica, biotecnológica ou preparação manufaturada, cuja administração seja

Disponível em: https://www.nucleodoconhecimento.com.br/engenharia-de-producao/industria- 
aplicada de forma individual ou coletiva, direta ou misturada com os alimentos, destinada à prevenção, ao diagnóstico, à cura ou ao tratamento das doenças dos animais, incluindo os aditivos, suplementos, melhoradores de produção animal, anti sépticos, desinfetantes de uso ambiental ou equipamentos, pesticidas e todos produtos que, utilizados nos animais e/ou no seu habitat, protejam, restaurem ou modifiquem suas funções orgânicas e fisiológicas. Compreendem-se ainda, nesta definição os produtos destinados à higiene e ao embelezamento dos animais.

Segundo Capanema et al. (2007), o principal objetivo das indústrias farmacêuticas veterinárias é a produtividade e saúde de diversos rebanhos, assegurar a garantia de qualidade dos alimentos que produzem e cuidar da saúde do bem-estar de animais domésticos.

Ainda de acordo com Bartlett e Ghoshal (2000), o mercado no setor farmacêutico é muito grande e competitivo, sendo assim as empresas precisam buscar se inovar para se destacar.

Complementando essa afirmação Bitencourt (2006), menciona em seu trabalho que um dos pontos importantes é atender as necessidades e demandas, ter uma boa assistência técnica, uma boa estrutura logística e se preocupar com a sustentabilidade da empresa em relação aos resíduos dos medicamentos e a forma correta de serem reutilizados.

\section{ESTUDO DE CASO}

O presente estudo de caso vem discorrer sobre uma indústria de medicamentos veterinários localizada na região de Ribeirão Preto. A indústria farmacêutica de medicamentos veterinários é responsável por manter a saúde e a produtividade dos diversos portes de animais em todo território nacional, bem como contribuir com a qualidade dos alimentos de procedência animal. Além disso, a indústria também é responsável por prover a saúde e o bem-estar de animais de companhia.

O objeto de estudo será o das embalagens de medicamentos, onde possui quatro pontos muito importantes. O primeiro é o da proteção, que tem como função proteger

Disponível em: https://www.nucleodoconhecimento.com.br/engenharia-de-producao/industriaveterinaria 
os produtos de danos no transporte ou distribuição; o segundo é a conservação com objetivo de prolongar a vida útil e diminuir as perdas por deterioração; o terceiro é informação referente ao produto (rastreabilidade); e o quarto é a conveniência e facilidade na utilização e consumo final do produto.

Um problema encontrado, a melhor maneira de fazer o descarte correto dessas embalagens de medicamentos e assim a empresa ganhar no aspecto ambiental e também na redução de custos foi o que mobilizou esse estudo de caso.

A falta de conhecimento do consumidor sobre a importância de não jogar embalagens de medicamentos em aterros, ou na classificação de lixo comum, contribui muito para o aumento de embalagens em locais e áreas que não foram feitas para receber este tipo de resíduo, e a ausência de postos de coletas que facilitariam o retorno para o local de origem, ou seja, o gerador a empresa.

A empresa alimenta o mercado com aproximadamente 3 toneladas/ano de embalagens das mais diversas apresentações e tamanhos, sendo desde caixas de papelão a frascos de plásticos e vidros, ampolas de vidros, seringas de plástico, agulhas, equipo, selos de alumínios, batoques de borracha, dentre outros materiais afins.

O plano de gerenciamento da logística reversa vem contar com uma equipe multidisciplinar da empresa composta pelo SESMT (Serviço Especializado de Engenharia de Segurança e Medicina do Trabalho), departamento Ambiental que possui a responsabilidade técnica na implantação e no setor de Suprimentos.

A seguir será apresentado como são classificados os resíduos.

\subsection{CLASSIFICAÇÃO}

A classificação de resíduo sólido é orientada pela NBR 10004/2004 e tem como objetivo classificar os resíduos e seus riscos potenciais no meio ambiente e na saúde pública, para que possa ter a sua destinação adequada. 
Resíduo sólido e semissólido é resultante de atividades industriais, domésticas, de saúde, comercial, agroindustrial, entre outras. São incluídos também os lodos de origem de sistema de estação de tratamento de água e efluentes, cujo o seu lançamento é (inviável/proibido) na rede pública de esgoto e/ou mananciais e corpos d’água.

A identificação dos resíduos sólidos deve ser rigorosa, criteriosa, e estabelecida com as propriedades físico químicas da matéria prima, insumos e processos de sua origem.

Tendo a sua classificação nas seguintes definições:

a) Resíduos classe I - Perigosos: são aqueles que apresentam em suas características e propriedade periculosidade, inflamabilidade, corrosividade, reatividade, toxicidade, patogenicidade, todas estas definições estão enquadradas pela NBR 10007.

b) Resíduos classe II Não perigosos

- Resíduo classe II A - Não inertes, são aqueles que não se enquadram nas descrições da classe I - perigosos, ou de resíduos classe II B. Tem em suas propriedades a biodegradabilidade, combustibilidade ou solubilidade em água

- Resíduo classe II B - Inertes, são os resíduos que podem ser destinados para aterros sanitários.

A seguir será apresentada a quantificação de resíduos sólidos gerados anualmente pela empresa.

\subsection{QUANTIFICAÇÃO DOS RESíDUOS SÓLIDOS}

Devido a sua geração e envio de resíduos sólidos no mercado a empresa tem estimado a quantidade de 3 toneladas/ano, de frascos e seringas de plástico e vidro, ampolas de vidro, baldes de plásticos de diversas apresentações de volume. 
Contendo diversos medicamentos injetáveis e orais, tais como: antibióticos, antiinflamatórios, hormônios, suplementação, ectoparasiticidas.

A seguir será apresentada a área destinada para o recebimento de resíduos sólidos denominada área de armazenamento temporário.

\subsection{ARMAZENAMENTO TEMPORÁRIO}

O armazenamento temporário é a área destinada para o recebimento de resíduos sólidos, que ficará à espera do processo de reciclagem, recuperação, tratamento, ou destinação final adequada.

A área destinada para receber estes resíduos deverá ser dotada de medidas de controle, com a finalidade de proteger a saúde pública e o meio ambiente.

Conter bacia de contenção com volume que suporte a quantidade depositada, ter o solo impermeável, ter cobertura delimitada, dique de contenção.

O acondicionamento destes resíduos deverá ser separado por classes, identificadas de acordo com suas características e propriedades.

Descaracterização das embalagens é um processo importante pois possibilita a prevenção ambiental e antecipa a destinação destes materiais, evita a reutilização e comercialização inadequada de resíduos consideráveis poluidores.

\subsection{DESTINAÇÃO FINAL}

Destinação final é a etapa onde o resíduo segue para aterros sanitários, estações de recuperação, tratamento e reciclagem.

Esta etapa busca tratar os resíduos a fim de deixá-los menos agressivos ao meio ambiente, e consequentemente a adequação para sua destinação final. 
Nos casos onde o tratamento se torna inviável pelas suas características e classe, a incineração é a mais adequada. Seguindo os padrões e autorizações dos órgãos públicos e apenas empresas autorizadas poderão realizar este processo.

A seguir serão apresentados os resultados alcançados pela implantação da logística reversa na empresa estudada.

\subsection{CRONOGRAMA}

As etapas a seguir irão tratar como ocorreu a implementação da logística reversa na empresa. Devido a se tratar de uma mudança que envolve vários setores e a busca de um lugar para armazenamento apropriado, a empresa optou por fazer em tempos distintos, no qual uma etapa precisava estar finalizando para a outra dar início.

Como se trata da colaboração de várias pessoas, foi realizada uma ação conjunta para mostrar a ideia da implementação, suas etapas e o que cada colaborador irá precisar fazer e os resultados que a empresa estava buscando. Segue abaixo:

\section{$1^{\circ}$ Etapa: Análise de quantidade de embalagens enviadas ao mercado.}

Através da rastreabilidade das notas fiscais, foi levantado a quantidade de produtos enviados ao mercado em determinado período e região, com isso, o desenvolvimento dos critérios de qual seria os produtos com maior quantidade e classe de resíduo.

\section{$2^{\circ}$ Etapa: Reconhecimento de área apropriada para armazenamento temporário.}

Nesta etapa foi realizada a deliberação do conselho na escolha da área que atendeu a demanda prevista para o armazenamento temporário, e a construção das instalações seguindo as normas vigentes. (NORMA 12235 da Associação Brasileira de Normas Técnicas - ABNT). 


\section{$3^{\circ}$ Etapa: Levantamento de custo de destinação das embalagens.}

Foram apresentadas propostas orçamentárias de empresas especializadas em destinação de resíduos, com tudo a empresa optou por realizar um adendo no contrato com a empresa já parceira que apresentou o custo mais favorável.

\section{$4^{\circ}$ Etapa: Disponibilização de frota e adequação dos itinerários.}

Como a empresa objeto de estudo terceiriza a entrega de suas mercadorias, foi proposto e aprovado que as mesmas companhias de transportes coletassem os resíduos, uma vez que já são aptas para este tipo de modalidade, com isso através do mesmo transporte pudesse realizar a atividade de entrega e coleta.

\section{$5^{\circ}$ Etapa: Análise dos postos de coletas.}

Para o início da implantação foram escolhidos os postos de coletas através de faturamento mensal e do mix de produtos vendidos pelo estabelecimento.

\section{$6^{\circ}$ Etapa: Orientação do corpo de gestão para a representação comercial.}

É de responsabilidade da representação comercial disponibilizar as informações e orientações para o consumidor, com a finalidade de conscientizá-lo sobre a importância de trazer ao posto de coleta as embalagens que receberão a destinação correta. A Figura 1 apresenta um cronograma com detalhamento das ações tomadas durante a implementação da logística reversa na empresa. 
Figura 1: Cronograma das Ações na Implementação do Sistema

\begin{tabular}{|l|c|c|c|c|c|c|c|c|c|c|c|}
\hline ATIVIDADES/MESES & $\mathbf{0 6 / 2 0 1 9}$ & $\mathbf{0 7 / 2 0 1 9}$ & $\mathbf{0 8 / 2 0 1 9}$ & $\mathbf{0 9 / 2 0 1 9}$ & $\mathbf{1 0 / 2 0 1 9}$ & $\mathbf{1 1 / 2 0 1 9}$ & $\mathbf{1 2 / 2 0 1 9}$ & $\mathbf{0 1 / 2 0 2 0}$ & $\mathbf{0 2 / 2 0 2 0}$ & $\mathbf{0 3 / 2 0 2 0}$ & $\mathbf{0 4 / 2 0 2 0}$ \\
\hline $\begin{array}{l}\text { 1) Análise da quantidade de } \\
\text { embalagens enviadas ao } \\
\text { mercado }\end{array}$ & $\mathbf{x}$ & $\mathbf{x}$ & & & & & & & & & \\
\hline $\begin{array}{l}\text { 2) Reconhecimento de área } \\
\text { apropriada para } \\
\text { armazenamento temporário }\end{array}$ & & $\mathbf{x}$ & $\mathbf{x}$ & & & & & & & & \\
\hline $\begin{array}{l}\text { 3) Levantamento de custo de } \\
\text { destinacão das embalagens }\end{array}$ & & & & $\mathbf{x}$ & $\mathbf{x}$ & & & & & & \\
\hline $\begin{array}{l}\text { 4)Disponibilização de frota e } \\
\text { adequação dos intinerários }\end{array}$ & & & & & & $\mathbf{x}$ & $\mathbf{x}$ & & & & \\
\hline $\begin{array}{l}\text { 5) Analise dos postos de } \\
\text { coletas }\end{array}$ & & & & & & & $\mathbf{x}$ & $\mathbf{x}$ & $\mathbf{x}$ & & \\
\hline $\begin{array}{l}\text { 6) Orientacão do corpo de } \\
\text { gestão para a representação } \\
\text { comercial }\end{array}$ & & & & & & & & & $\mathbf{x}$ & $\mathbf{x}$ & $\mathbf{x}$ \\
\hline
\end{tabular}

Fonte: Criação do Autor.

\section{RESULTADOS/PROPOSTAS}

De forma a amenizar o impacto ambiental das embalagens se fez necessário mudar a conduta interna e externa para atingir os objetivos de uma nova implementação de logística atribuída na empresa.

Considerando que as primícias da logística reversa trazem como redução, reciclagem e destinação final, o retorno no período de junho de 2019 a maio de 2020 em resíduos sólidos foi de aproximadamente 1.2 toneladas.

A necessidade de remeter o vasilhame para o gerador, ou seja, a empresa tem a responsabilidade legal de destinação final e adequada para cada classificação de resíduo gerado mostrou ser grande uma vez que esses resíduos geram resultados positivos para a empresa.

A geração desses resultados positivos não contribui somente na questão do impacto socioambiental, mas também na redução de custos com embalagens, devido o retorno financeiro das vendas destas embalagens aptas a serem processadas em forma de reciclagem.

Disponível em: https://www.nucleodoconhecimento.com.br/engenharia-de-producao/industriaveterinaria 
Outro ponto importante desses resultados seria a conscientização dos colaboradores, que precisam se moldar às novas mudanças e buscam se ajudar já que o sistema envolvia vários setores para funcionar.

Contudo também houve dificuldades encontradas na parte de orçamentos, devido à ausência de planejamento dos custos previstos para atender esta nova situação. Outra dificuldade seria a do armazenamento temporário, pois necessitou a adequação de uma área para acondicionar as embalagens que foram recebidas no período citado.

\section{CONCLUSÕES}

O método proposto discorre sobre um estudo de caso que apresenta a situação de embalagens de medicamentos em sua problemática a ausência de gerenciamento de resíduos sólidos.

As empresas e suas cadeias produtivas precisam se enquadrar e atender as legislações ambientais vigentes, como também podem enxergar como um diferencial socioambiental em suas negociações comerciais, trazendo uma relevância sobre os seus concorrentes.

A ausência de informação sobre a devolução das embalagens para o gerador, dificulta a implantação de medidas mais efetivas, com isso traz impactos para a sociedade e para o meio ambiente.

Esperamos com o presente estudo de caso estimular novas pesquisas para 0 aprofundamento e discussões sobre a importância da logística reversa em nossa sociedade.

\section{REFERÊNCIAS}

ADLMAIER, D.; SELLITTO, M. A. Embalagens Retornáveis para Transporte de Bens Manufaturados: Um Estudo de Caso em Logística Reversa. Produção, v.17, n.2, p. 395-406, 2007. 
BALLOU, R. H. Gerenciamento da cadeia de suprimentos. 4 ed. Rio Grande do Sul: Bookman, 2001.

BARRETO, W. D. Processo de Desenvolvimento de Fármacos Veterinários, Lorena - São Paulo, 2013.

BARTLETT, C.; GHOSHAL, S. Lessons from Late Movers. Harvard Business Review, v. 78, n. 2, p. 132-142, mar./apr. 2000.

BITENCOURT, C. C. Competência gerencial e aprendizagem nas organizações. São Leopoldo: Editora Unisinos, 2005.

BRASIL. Decreto № 5.053, de 22 de Abril de 2004. Aprova o Regulamento de Fiscalização de Produtos de Uso Veterinário e dos Estabelecimentos que os Fabriquem ou Comerciem, e dá outras Providências. Disponível em: http://www.planalto.gov.br/ccivil_03/_Ato2004-2006/2004/Decreto/D5053.htm\#art4. Acesso em 22/08/2020.

BUENO et al. Aplicação da Logística Reversa no Descarte de medicamentos Vencidos: Estudo de Caso em uma Industria Farmacêutica. South American Develpment Society Journal, v.2, n.6, 2016.

CAPANEMA, L. X. L. et al. Panorama da Indústria Farmacêutica Veterinária. BNDES Setorial, Rio de Janeiro, 2007. Disponível em: https://web.bndes.gov.br/bib/jspui/bitstream/1408/2530/1/BS\%2025\%20Panorama\% 20da\%20Ind\%C3\%BAstria\%20Farmac\%C3\%AAutica\%20Veterin\%C3\%A1ria_P.pdf. Acesso em 22/08/2020.

CASTRO et al. Avaliação do Processo de Logística Reversa em uma empresa Farmacêutica. XIX Simpósio de Pesquisa Operacional e Logística da Marinha, Rio de Janeiro- RJ, 2019.

GARCIA, M. G. Logística Reversa: uma alternativa para reduzir custos e criar valor. XIII SIMPEP, Bauru - São Paulo, 2006. 
LEITE, B. Z.; PAWLOWSKY, U. Alternativas de minimização de resíduos em uma indústria de alimentos da região metropolitana de Curitiba. Eng. Sanit. Ambient.,10, 2, p.96-105, 2005.

MINISTERIO DO MEIO AMBIENTE. Site oficial do Ministério do Meio Ambiente. Disponível em: https://www.mma.gov.br/responsabilidade-socioambiental/producaoe-consumo-sustentavel/consumo-consciente-de-embalagem/impacto-dasembalagens-no-meioambiente.html\#: :text=No\%20Brasil\%2C\%20aproximadamente\%20um\%20quinto,qu ase\%2020\%20quil\%C3\%B4metros\%20de\%20estrada. Acesso em 20/08/2020.

MOTTA, W. H. Logística Reversa e a Reciclagem de Embalagens no Brasil. VII Congresso Nacional de Excelência em Gestão, p. 5-9, 2011.

MUELLER, C. F. Logística Reversa, Meio Ambiente e Produtividade. Grupo de Estudos Logísticos Universidade Federal de Santa Catarina, Florianópolis - Santa Catarina, 2005.

SHEHATA, N. G. Gerenciamento de Resíduos Sólidos Industriais da Indústria Farmacêutica, Estudo de Caso: União Química Farmacêutica Nacional AS. Dissertação de Mestrado, Universidade Católica de Brasília, Brasília, 2012.

STOCHER, F. M. A Logística Reversa no Setor Farmacêutico: Um Estudo em Santana do Livramento/ RS. Trabalho de Conclusão de Curso em Administração, Universidade Federal do Pampa, Santana do Livramento-RS, 2018.

Enviado: Setembro, 2020.

Aprovado: Outubro, 2020. 